\title{
Aktif sabit ortodontik tedavi sırasında meydana gelen dental travma: Vaka raporu
}

\author{
Neslihan Ebru Şenışık ${ }^{\alpha}$, Filiz Aydoğan ${ }^{\alpha}$
}

Bașvuru Tarihi: 04 Nisan 2017

Yayına Kabul Tarihi: 07 Temmuz 2017

Selcuk Dent J, 2017; 4: 144-152 (Doi: 10.15311/selcukdentj.303967)

\section{öz \\ Aktif sabit ortodontik tedavi sırasında meydana gelen dental travma: Vaka raporu}

$\mathrm{Bu}$ vaka raporunun amacı sabit ortodontik tedavi sırasında dental travmaya maruz kalan hastanın tedavisini sunmaktır. Kliniğimizde beş aydır sabit ortodontik tedavi görmekte olan 16 yaşında bayan hasta travma geçirmiş ve travmadan iki gün sonra kliniğimize gelmiştir. Hasta evinde senkop geçirdiğini ve düştüğünü belirtmiştir. Ekstraoral olarak alt dudakta laserasyon intraoral olarak alt santral keserlerde lateral lüksasyonla birlikte ekstrüzyon gözlenmiştir. Travmadan hemen sonra pulpanın vitalitesinin net olarak değerlendirilememesinden dolayı kök kanal tedavisi ertelenmiştir. Travmadan sonra her iki travmaya uğramış diş üzerindeki aktif ortodontik kuvvet kaldırımıştır. 7 ay sonra travmaya maruz kalan dişlerin pulpalarının vital olduğu tespit edilmiştir. Daha sonra hafif ortodontik kuvvetlerle sıralama ve seviyeleme yapılmış, başlangıçta planlandığı gibi estetik bir gülüş ve ideal bir okluzyon elde edilmiştir. Aktif ortodontik tedavinin bitiminden on iki ay sonra alınan periapikal radyografta madibular santral keser dişlerin pulpasında kısmi obliterasyon tespit edilmiştir. Her altı ayda bir rutin klinik ve radyografik değerlendirme gerekmektedir.

\section{ANAHTAR KELIMELER}

Dental travma, lateral lüksasyon, sabit ortodontik tedavi

Dental travma (travmatik dental yaralanma) dişleri ve oral kavite çevresindeki yumuşak ve sert dokuları etkiler. Dünya genelinde yapılan araştırmalara göre dental travma genellikle sportif aktiviteler, düşmeler, trafik kazaları ve kavgalar sonucu görülür ve çoğu zaman acil müdahale gerektirir. ${ }^{1,2}$ Dental travma vakalarına müdahale edilirken, tedavi rehberleri her hasta için standart olarak uygulanamayabilir. Her vaka kendisine özgü koşullarda değerlendirilip buna göre tedavisi yapılmalıdır. Hastanın genel sağlığı, travmanın ciddiyeti ve tipi, hastanın kronolojik ve dental yaşı, dental ve anatomik gelişim durumu, travma sırasında ağız içerisinde bir aygıt taşıyıp taşımaması, tedavi için belirleyici olan faktörlerden bazılarıdır.,4 Literatürde sayıca az bildirilmiş olmakla beraber, ${ }^{5,6}$ ortodontik tedavi sırasında ağzında

\section{ABSTRACT}

Dental trauma during fixed orthodontic therapy: A case report

The purpose of this case report was to present the treatment of a patient suffering from accidental dental trauma during fixed orthodontic treatment. A 16-year-old girl that was receiving fixed orthodontic therapy in our clinic for 5 months came back two days later after a dental trauma. She revealed that she had a syncope and fell down in her house with the effect of syncope. Extraorally, lower lip laceration was observed. Intraorally, lateral luxation associated with extrusion for lower central incisors $(31,41)$ was diagnosed. Root canal treatment was delayed because it was not possible to determine the definite result of pulp vitality response of traumatized teeth immediately after the injury. After trauma, active orthodontic force was removed from both of traumatized teeth. After 7 months, it was determined that pulp vitality of traumatized tooth was remained. Then levelling and alignment was performed with light orthodontics forces. An esthetic smile and ideal occlusion was achieved as it was planned initially. Twelve months after the end of active orthodontic treatment, sectional pulp obliteration was examined in perapical radiographs of both mandibular central incisors. Rutine clinical and radiographic examination is needed in every 6 months.

\section{KEYWORDS}

Dental trauma, lateral luxation, fixed orthodontic treatment

ortodontik ataçmanlar bulunan hastalar da dental travmaya maruz kalabilmektedir.

Ortodontik tedavi sırasında dental travma meydana geldiğinde tedavi açısından izlenecek yol klinik deneyime ve literatürde sunulmuş bireysel olgu raporlarına göre yapılmaktadır. ${ }^{5-7}$ Çoğu travma vakası multidisipliner tedavi yöntemlerini içeren (pedodonti, oral cerrahi, endodonti, ortodonti, restoratif diş tedavisi ve protetik diş tedavisi vb.) bireysel bir yaklaşıma intiyaç duymaktadır. Uygulanacak tedavilerin başarısı ise kapsamlı ve dikkatli bir muayene sonucu konulacak tanı ile mümkündür.

\footnotetext{
${ }^{\alpha}$ Süleyman Demirel Üniversitesi Diş Hekimliği Fakültesi Ortodonti AD, Isparta
} 
Muayene öncesinde öncelikle kapsamlı bir hasta hikayesi alınır. Hastanın genel sağlık durumu, yaralanmanın zamanı, travmanın direkt veya indirekt oluşu belirlenir. Dokuların iyileşme kapasitesinin durumunu belirlemek için daha önce aynı bölgeye travma alıp almadığı, o bölgeye önceden herhangi bir tedavi yapılıp yapılmadığı, dişin destek dokularında veya pulpadaki hasarı gösteren kriterlerden spontan diş ağrısı, sıcak - soğuk, tatlı - ekşi gıdalara duyarlılığı sorgulanır. Klinik muayenede ağız dışı dokular ağız içi muayenede ise travma bölgesindeki periodontal dokular, alveol kemiği ve dişler dikkatlice muayene edilir. Oklüzyondaki anormallikler alveol ve çenedeki kırıklara işaret eder. Dişlerin dokunma sırasındaki duyarlılığı, dişlerde lüksasyon olup olmadığı tespit edilir. Kök kırıklarının lokalizasyonuna göre dişte lüksasyon görülür. Kök kırığının mobilitesi kırık hattı krona yaklaştıkça artar. Perküsyona duyarlılık periodontal liflerdeki yaralanmaları işaret eder. Termal testler ve vitalometre uygulamaları travma nedeniyle yaralanan dişlerde pulpanın canlılığını saptamak için kullanılır. Travmayı takip eden günlerde diş şokta olabilir ve bu nedenle geçici olarak pulpa cevabı azalmış olabilir. Lüksasyon yaralanmalarında da cevap geçici olarak azalabilir. Tekrarlanan testlerin sonucunda reaksiyonların birkaç hafta veya ay içinde normale döndüğü gözlenebilir. Dişler farklı sürme ve gelişim dönemlerinde de farklı cevaplar verebilirler. Kök gelişiminin henüz tamamlanmadığı dişlerde vitalite testlerine daha geç cevap alınır. Radyolojik muayene ile genç bireylerde travma sonucu yaralanan dişin kök gelişimi gözlenir. Ek olarak dişin kökünde bir kırık olup olmadığı, varsa yeri, dişte meydana gelen yer değiştirmeler, periodontal dokularda oluşan hasarlar ve alveol kemikteki kırıklar saptanabilir. ${ }^{8}$

Beklenmedik bir şekilde gelişen dental travma hastanın oral fonksiyonlarını ve psikolojisini etkileyebilmektedir. Sabit ortodontik tedavi gören bireylerde dental travma meydana geldikten sonra ağrıyı ve travmanın dişler, periodontal dokular üzerindeki olumsuz etkilerini mümkün olan en kısa sürede elimine etmek gereklidir. Sabit ortodontik tedavinin hangi aşamasında olursa olsun, tedavi sırasında meydana gelen dental travma aktif ortodontik tedavinin rutin işleyişini bozar. Travma bölgesindeki ilk acil müdahale ağrının dindirilmesi ve ortodontik kuvvetin hızla travma bölgesindeki dişler üzerinden kaldırımasıdır. Ardından dental travmanın şiddetine göre multidisipliner tedavi yöntemlerini içeren bireysel bir yaklaşım ile tedavi yapılır.

Bauss ve ark. ${ }^{6}$ ortodontik tedavi sırasında dental travma görmüş vakalarda dental travmanın çeşidine göre farklı tedavi yaklaşımları bildirmişlerdir. Dişin sert dokusunu ilgilendiren mine ve mine-dentin kırıklarında ya da hafif periodontal yaralanmalarda (sublüksasyon), ortodontik kuvvet 2-3 ay süresince kesilmekte ve travma görmüş dişler sabit ortodontik tedavi dışında bırakılmaktadır. Travma sonucu ekstrüzyon veya lateral lüksasyon meydana gelen vakalarda ise travma görmüş dişlerin ve soket duvarlarında meydana gelen kırıkların dikkatlice repoze edildiği ve 0.016 × 0.022 inç kalınlığındaki paslanmaz çelik ark teli ile dişlerde fiksasyon yapıldığı belirtilmiştir. Üç haftalık fiksasyon süresince travma görmüş dişler yanındaki dişlere splintlenmektedir. İntrüziv lüksasyon vakalarında 3-4 hafta spontan erüpsiyon için beklenmektedir. Bu süreç içerisinde dişte spontan sürme ile yeniden eski duruma dönme görülmezse elastik traksiyon uygulaması ile ortodontik ekstrüzyon yapılmaktadır. Sonrasında $0.016 \times 0.022$ inç paslanmaz çelik ark teli ile 3-4 haftalık fiksasyon gerçekleştirilir. Şiddetli periodontal yaralanmalarda ortodontik diş hareketine 5-6 ay ara verildiği belirtilmiştir. ${ }^{9}$

Ortodontik tedavi sırasında travmatik olarak yaralanmış dişler için literatür ışığında,8,10-14 tedavi yönetimini özetleyen Owtad ve ark. ${ }^{5}$ dişe gelen hafif travma olarak değerlendirilen, sadece travma görmüş dişte hassasiyet semptomu ile tanımlanan sadme (sarsıntı) ve displaze dişte gevşeme ile karakterize sublüksasyon durumunda birkaç hafta yumuşak diyet önermişlerdir. Yeniden ortodontik kuvvet uygulaması için ise 3 ile 3-6 ay beklenmesi gerektiğini bildirmişlerdir. Orta dereceli travma olan ve travma görmüş dişin kronunun palatinale kökünün ise labiale displaze olduğu lateral lüksasyon durumunda dişin, lokal anestezi altında repoze edildikten sonra hafif esnek bir splint ile stabilize edilmesini, endodontik kanal tedavi yapılmasını ve ortodontik tedaviye 6 ay sonra devam edilmesini önermişlerdir. Orta derece travmalardan, travma görmüş dişin periodotal ligamentinin sıkıştığı veya oblitere olarak dişin kronunun bir miktar veya tamamen intrüze olduğu durumda, dişin lokal anestezi altında repoze edilmesi, endodontik tedavi yapılması ve ortodontik kuvvet uygulaması için 6 ay beklenmesi önerilmiştir. Kısmi ekstrüzyon durumunda ise dişin, lokal anestezi altında repoze edilmesini, hafif esnek bir splint ile stabilize edilmesini ve ortodontik tedaviye 6 ay sonra devam edilmesini önermişlerdir. Sabit ortodontik tedavi sırasında çok nadir karşılaşılan, dişin alveol soketinden tamamen çıktığı şiddetli travmalardan avülsiyon durumunda, replantasyon, rijit fiksasyon, sürekli takip ve ortodontik kuvvet uygulama için 6 aylık bekleme süresi önermişlerdir. Şiddetli travma sayılan pulpanın dahil olmadığı kron kırıklarında dişin kronunun restorasyonu ve ortodontik kuvvete 3 ay sonra devam edilmesi önerilmiştir. Kök kırığının radyografik ve klinik olarak gözlendiği durumda ise 
endodontik ve cerrahi tedavi sonrası iyileşmeyi takiben ortodontik tedaviye 1-2 yıl sonra tekrar başlanabileceğini bildirmişlerdir. ${ }^{5}$ Travma sonrası dişe ortodontik kuvvet uygulanmayan süreçte her 3 ayda bir periapikal radyograf ile köklerin durumunun, vitalite testi ile pulpal durumun takibi önemlidir. ${ }^{6,10,13}$ Ortodontik tedavi sırasında bireye özgü tedavi aygıtlarının ve modifikasyonlarının seçimi, hafif kuvvetlerin kullanılması, kök rezorpsiyonu riski için düzenli radyografik takip ve ortodontik tedavinin bitmesinin ardından düzenli takibin devamlılığı önemlidir. Ortodontik diş hareketinin pulpada ciddi derecede enflamasyon yarattığı bilinmektedir ancak bu durum genellikle geri dönüşümlüdür. Bununla birlikte daha önceden travma geçirmiş dişlerde inflamatuar cevap daha belirgindir. ${ }^{10}$ Ortodontik tedaviden bir yıl önce travmaya maruz kalmış dişlerde ortodontik tedavi sırasında kök rezorpsiyonu riski ${ }^{15}$ ve ortodontik tedavi sırasında ciddi periodontal yaralanma geçiren ve total pulpa obliterasyonu görülen dişlerde, ortodontik tedavinin ilerleyen aşamalarında pulpa nekrozu riski artar. ${ }^{6}$

Günümüzde sabit ortodontik tedavinin pek çok bireye ulaştırılabilmesi ve dental travmanın da prevelansının yüksek olması sebebiyle ortodontik tedavi sırasında meydana gelebilecek travmanın güncel bilgiler ışığında yönetilmesi önemlidir. Her bir travma vakasının kendine has özellikte olması ve yönetilmesi sırasında bireyin tedaviye cevabının varyasyon gösterebilmesi sebebiyle sabit ortodontik tedavi sırasında meydana gelen travmanın teşhisi, tedavisi ve tedavi ile elde edilen sonucun sunulması önemlidir. Bu sebeple bu vaka raporunun amacı aktif ortodontik tedavi sırasında dental travmaya maruz kalan ve tedavisi başarı ile gerçekleştirilen tedavi sonrası 12 aylık takibi yapılmış bir vakayı sunmaktır.

\section{OLGU SUNUMU}

Süleyman Demirel Üniversitesi Diş Hekimliği Fakültesi Ortodonti Anabilim Dalı'na başvuran 16 yaşındaki bayan hastanın esas şikâyeti "köpek dişinin yukarıda olması" idi. Hastada yapılan ekstraoral muayenede düz bir profilinin olduğu, intraoral muayenede sağ üst kanin dişin vestibülde suprapozisyonda olduğu, bütün birinci büyük azı dişlerinde ve alt sol ikinci büyük azı dişinde çeşitli büyüklüklerde amalgam ve kompozit restorasyonlar olduğu tespit edildi (Resim 1 a-j). Radyografik değerlendirmede 20 yaş dişleri hariç tüm dişlerinin ağızda olduğu, sefalometrik analizde ANB açısına göre iskeletsel Sınıf I olduğu belirlendi (Resim 2 a-c) (Tablo 1). Sabit ortodontik mekanikler ile yapılması kararlaştırılan ortodontik tedavisinde tek tarafta sağ üst birinci premolar dişin çekilmesine ve orta hattı kaydırmadan suprapozisyondaki kanin dişin seviyelenerek arka dahil edilmesine karar verildi. Vakanın alt üst dişlerinin ışık ile sertleşen ortodontik adeziv sistem (Transbond XT, 3M Unitek, St. Paul, $\mathrm{MN}, \mathrm{ABD}$ ) ile braketlenmesinin (Microtech Plus Brackets- 018" Roth, Ortho Technology Inc, Florida, ABD) ardından üst sağ birinci premolar dişin çekimi yapıldı. Alt ve üst çenelerde sıralama-seviyelemeyi takiben üst çenede lace-back ile kanin distalizasyonu yapılmaya başlandı. Kanin distalizasyonu sırasında moderate ankraj prensibi esas alındı. Ortodontik tedavinin başlamasından yaklaşık 5 ay sonra hasta, evinde bilinmeyen bir sebeple senkop geçirdiğini ve düştüğünü bildirdi. Travmadan iki gün sonra kliniğimize geldiğinde hastanın dudaklarında büyük ölçüde iyileşen ancak dikkat çeken laserasyon tespit edildi (Resim 3). Hastanın ağız içi klinik muayenesinde alt kesici diş çevre dokularında yaralanma, alt santral kesici diş kronlarında $(31,41)$ linguale hareket gözlendi (Resim 3a-f). Ek olarak alt santral kesici dişler uzamıştı (Resim 3g). Mevcut olan ark tellerinden dolayı santral dişler immobildi. Alveoler proçesin lingualinde kırık hattı palpe edildi (Resim 3). Travma kuvvetinin etkisiyle ağız içerisinde bir önceki seans ligature edilen $0.016 \times 0.022$ inç paslanmaz çelik ark telinin, mandibuler santral kesicilere inset bükümü yapılmışçasına dişler ile beraber linguale eğilmiş olduğu gözlendi (Resim 3). Travma sonrası yapılan radyolojik değerlendirmede herhangi bir kök ve/veya kron kırığının olmadığı belirlendi. Periodontal ligament aralığının apikalde ve lateralde genişlediği izlendi (Resim 3i). Her iki alt santral kesici dişte $(31,41)$ lingual yönlü lateral lüksasyona eşlik eden ektrüzyon tespit edildi.

Travma kuvvetinin etkisiyle alt çenede eğilmiş olan $0.016 \times 0.022$ inç paslanmaz çelik ark teli çıkartılıp, travmaya uğramış dişler aktif ortodontik kuvvetin dışında bırakıldı. Vitalometre ile yapılan vitalite testi negatif sonuç verdi. Dişin ileride vitalite testine olumlu sonuç verme ihtimali göz önünde bulundurularak, kanal tedavisi hemen yapılmadı. Ancak ileride olası pulpa nekrozu komplikasyonuna karşı vaka uyarıldı. Dişlerin pulpal durumunun takibine karar verildi. Üst çenede herhangi bir hasar gözlenmedi. Travma sonrası alt santral kesici dişlerin olması gereken yerlerinin yandaki dişler tarafından kapatılmış olması sebebiyle dişler eski yerine repoze edilemedi ve oldukları yerde bırakıldı. Alt santral kesici dişler lingualden esnek retainer teli ile (esnek splint) splintlendi. Alt çenede travma görmüş santral kesici dişlerin dışında kalan dişlere 0.016x0.022 inç $\mathrm{NiTi}$ ark teli uygulandı, pasif açık coilspring konularak santral kesici dişlerin boşluğu tutuldu. Dört hafta sonra travma görmüş dişlerin dişındaki dişlere $0.016 \times 0.022$ inç paslanmaz çelik ark teli uygulandı ve travma görmüş dişler için gerekli olan yer açık coilspring kuvveti ile açılmaya başlandı. Bu 
uygulamaya yeterli yer açılıncaya kadar devam edildi. Üst çenede ise sabit ortodontik tedavi sürdürüldü.

Yedi ay sonra yapılan ağız içi muayenede alt santral keser diş bölgesinde dişeti ve dişlerin sağlıklı olduğu izlendi. Alınan periapikal radyografta herhangi bir kök rezorpsiyonu veya pulpa obliterasyonu gözlenmedi (Resim 4). Mandibuler santral keser dişlerin vitalitesi dijital vitalometre ile değerlendirildi ve vital olduğu tespit edildi. Önceden aktif açık coilspringle yerleri açılan travma görmüş alt santral keser dişler 0.012 inç $\mathrm{NiTi}$ ark teline ligatüre edildi. Dört haftalık süreç sonunda dişlerin hareket ettiği gözlendi ve mandibuler dişler sırası ile 0.014, $0.016,0.016 \times 0.016$ ve $0.016 \times 0.022$ inç $\mathrm{NiTi}$ ark telleri ile seviyelendi. Mandibuler santral kesici dişlere travma sonrası hafif kuvvetler uygulanarak yapılan sabit ortodontik tedavi ideal oklüzyonun elde edilmesi ile başarılı bir şekilde bitirildi (Resim 5). Travmanın hemen sonrası 7 ay boyunca alt santral kesici dişlere hiçbir kuvvet uygulanmadı, 7 ay sonra başlanan hafif kuvvet uygulama süreci, dişlerin seviyelenmesi ve tedavinin bitirilmesi ile beraber altı ay sürmüştü. Toplam tedavi süresi 19 aydır. Retansiyon sürecinde aynı zamanda splint görevi gören lingual retainer (Hilgers Bond-aBraid $\AA$ andRetainium $\AA \quad$ LingualRetainer Wire. RelianceOrthodontic Productslnc., Itasca, IL, ABD) kullanıldı. Lingual retainer çok sarımlı telden ağız içinde direkt bükülerek yapıldı. Ortodontik tedavi sonunda ideal okluzyon sağlandı ve dişlerin vitalitesi korundu (Resim 5 a-j). Tedavi sonu sefalometrik analiz sonuçları Resim 6' da verilmiştir (Tablo 1)

Hastanın 12 ay sonraki kontrolünde alt santral keser dişlerin vital olduğu, kök rezorbsiyonunun olmadığı ancak alınan periapikal radyografide kök kanallarında kısmi pulpa obliterasyonu olduğu tespit edilmiştir (Resim 7). Vakanın alt santral kesici dişlerinde ilerleyen zamanlarda oluşabilecek pulpa nekrozu ve/veya kök rezorpsiyonu intimali sebebiyle 6 aylık rutin takibinin yapılmasına karar verilmiştir.
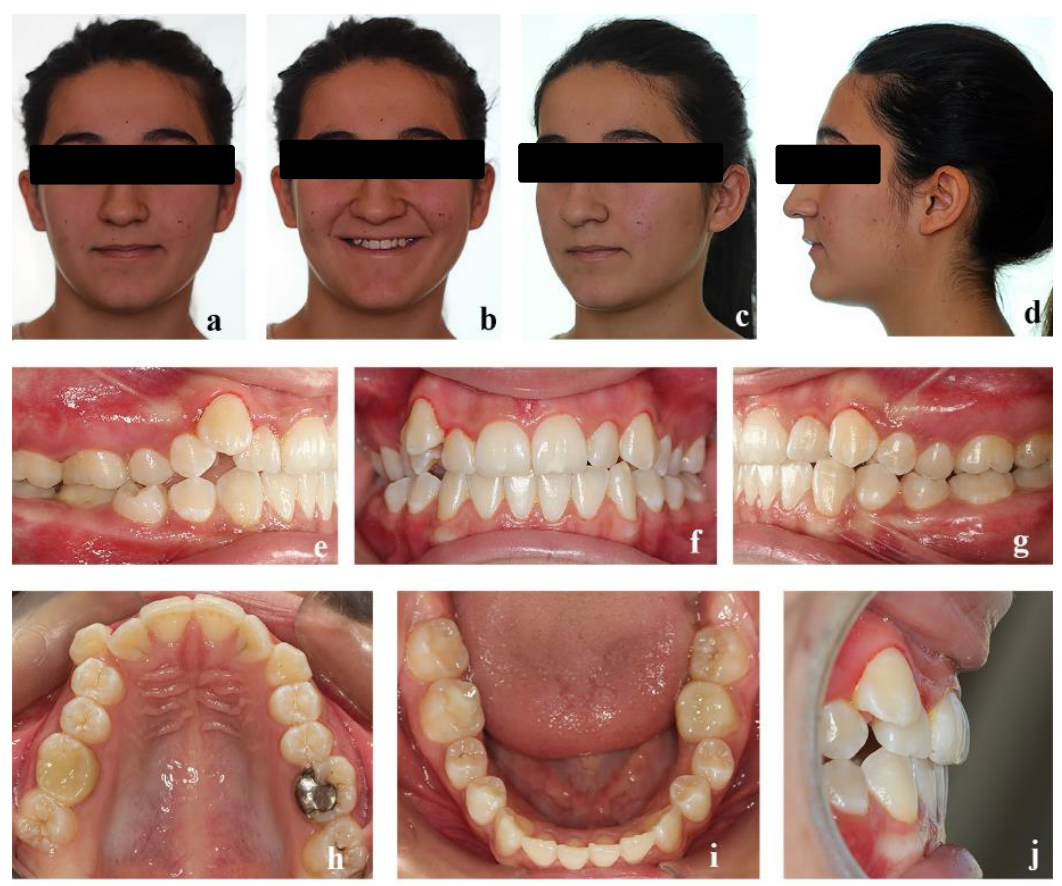

Resim 1.

Sabit ortodontik tedavi öncesi ağız dışı ve ağız içi fotoğraflar a, b, c, d) Sabit ortodontik tedavi öncesi cephe, 3/4 ve profil fotoğrafları $\mathbf{e}, \mathbf{f}, \mathbf{g}, \mathbf{h}, \mathbf{i}, \mathbf{j}$ ) Sabit ortodontik tedavi öncesi ağı içi fotoğraflar
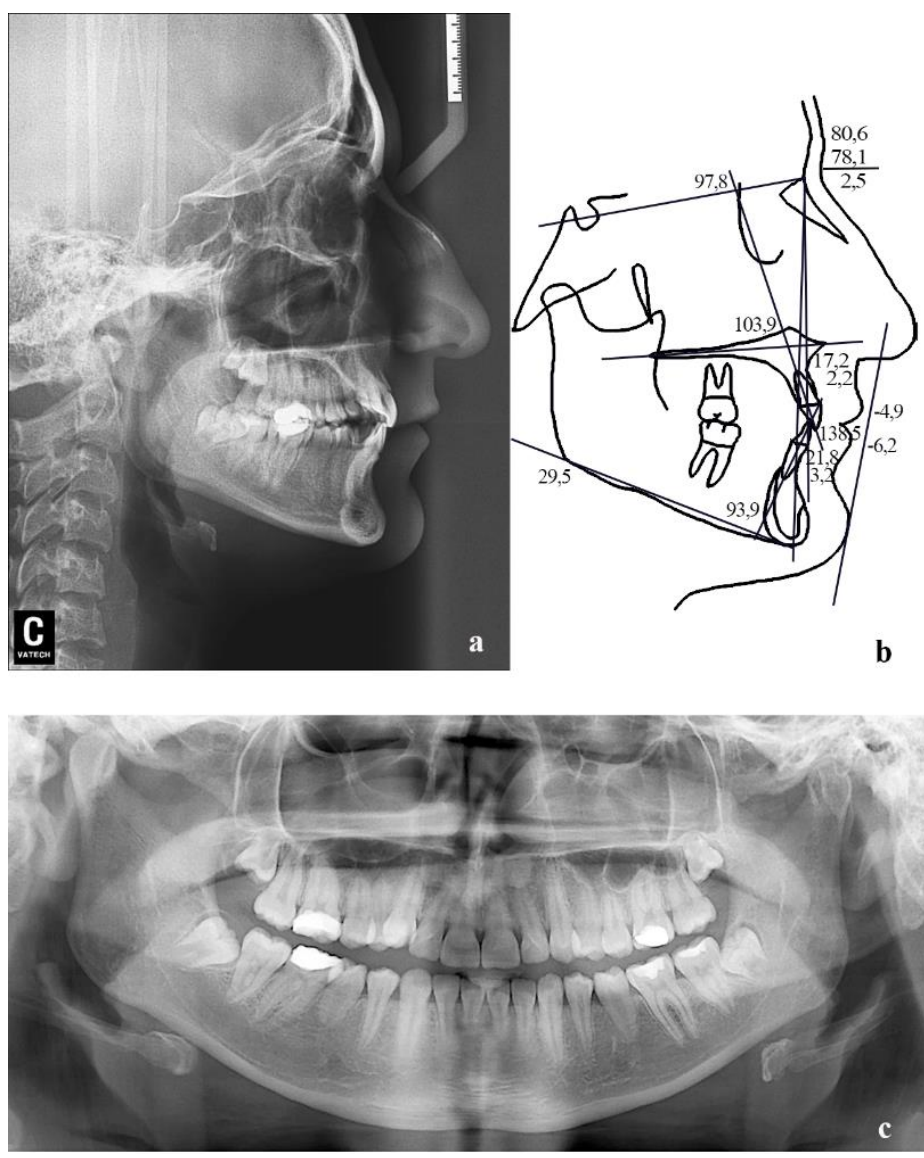

Resim 2.

Sabit ortodontik tedavi öncesi radyografiler ve analizler

a, b) Sabit ortodontik tedavi öncesi lateral sefalometrik radyografi ve analizi e, f, $\mathbf{g}, \mathbf{h}, \mathbf{i}, \mathbf{j})$ Sabit ortodontik tedavi öncesi panoramik radyografi 

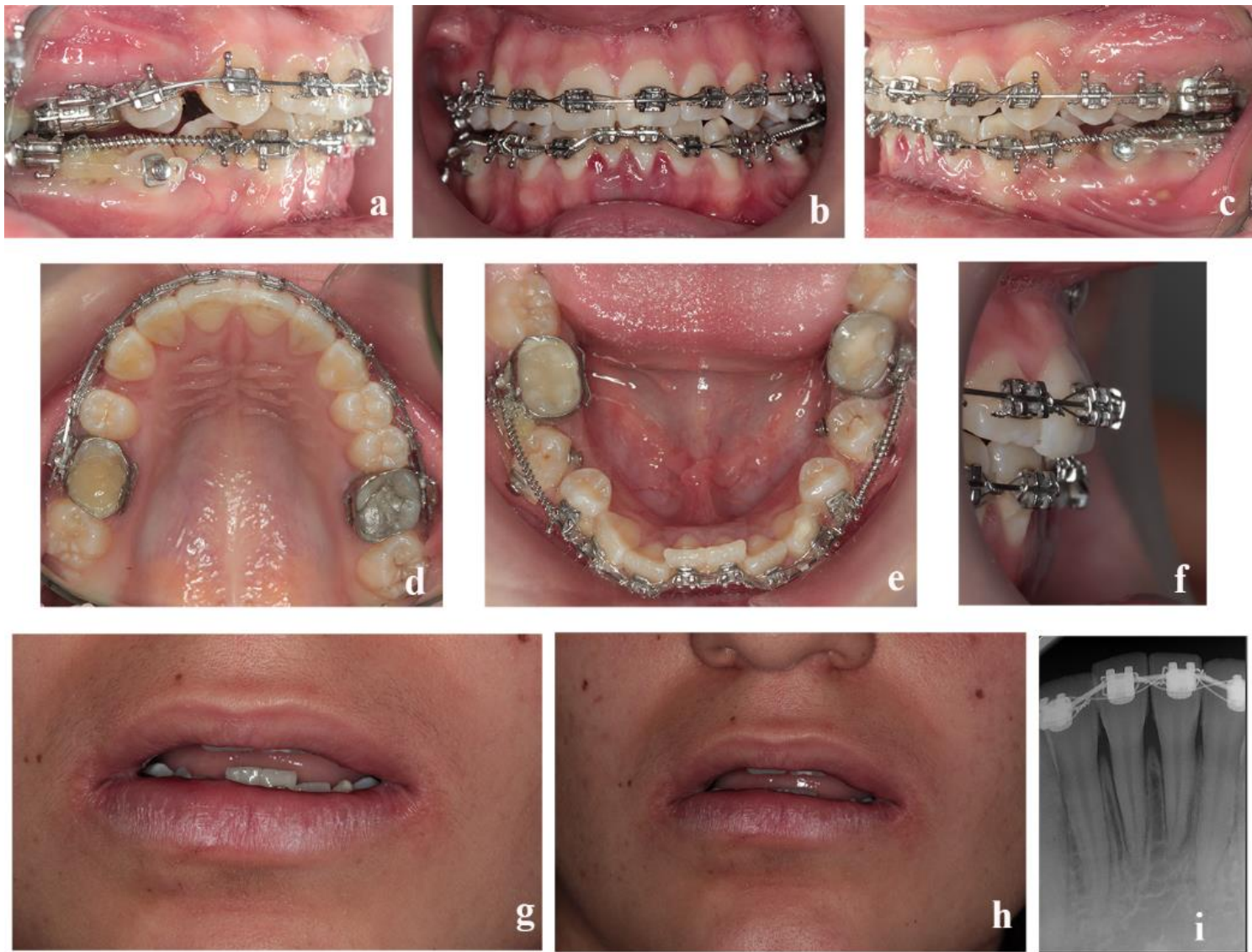

Resim 3.

Sabit ortodontik tedavi sırasında meydana gelen travma sonrası alınan ağız içi ve ağız dışı fotoğraflar ve periapikal radyograf a, b, c, d, e, f) Ağız içi fotoğraflar g,h) Ağız dışı fotoğraflar i) Travma sonrası periapikal radyograf
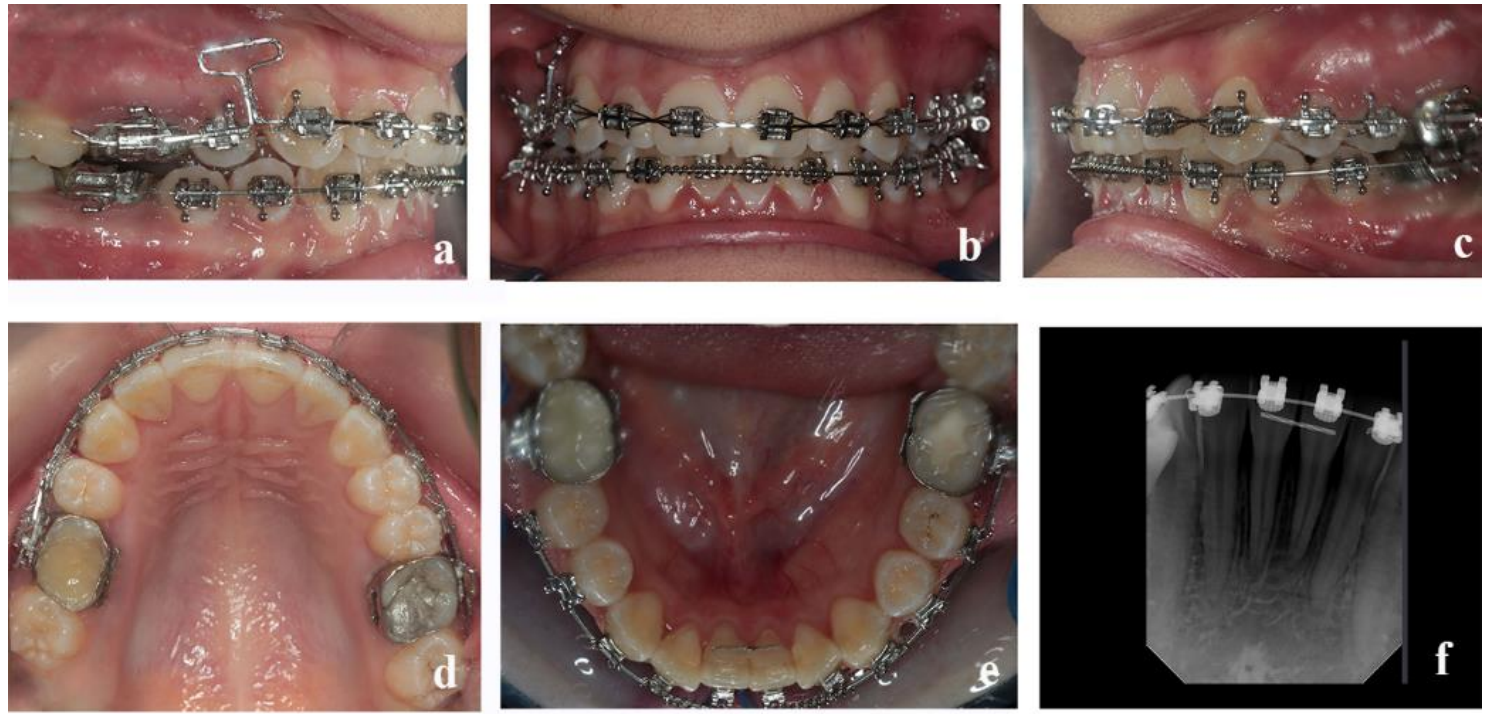

Resim 4.

Travmadan 7 ay sonra alınan ağız içi fotoğraflar ve periapikal radyograf

a, b, c, d, e) Ağız içi fotoğraflar, travma sonrası süreçte alt santral keser dişlere esnek splint yapılmış ve alt santral keser dişlerin bulunduğu yer coil spring ile tutulmuștur. 7 aylık süre boyunca alt santral keser dişlere ortodontik kuvvet uygulanmamıştır

f) Periapikal radyograf 

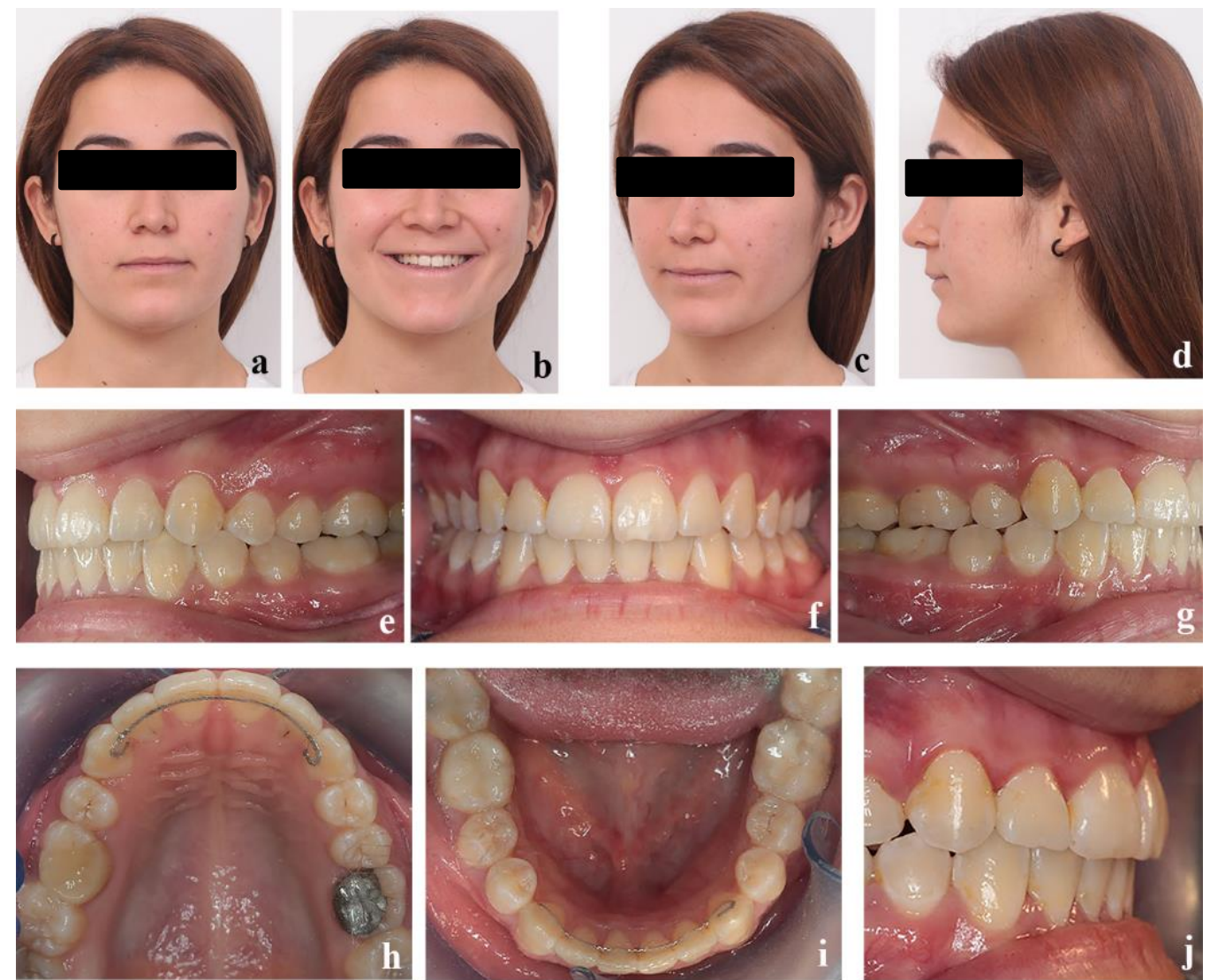

Resim 5.

Sabit ortodontik tedavi sonrası ağız dışı ve ağız içi fotoğraflar a, b, c, d) Sabit ortodontik tedavi sonu cephe, $3 / 4$ ve profil fotoğrafları e, f, $g, \mathbf{h}, \mathbf{i}, \mathbf{j})$ Sabit ortodontik tedavi sonu ağız içi fotoğraflar
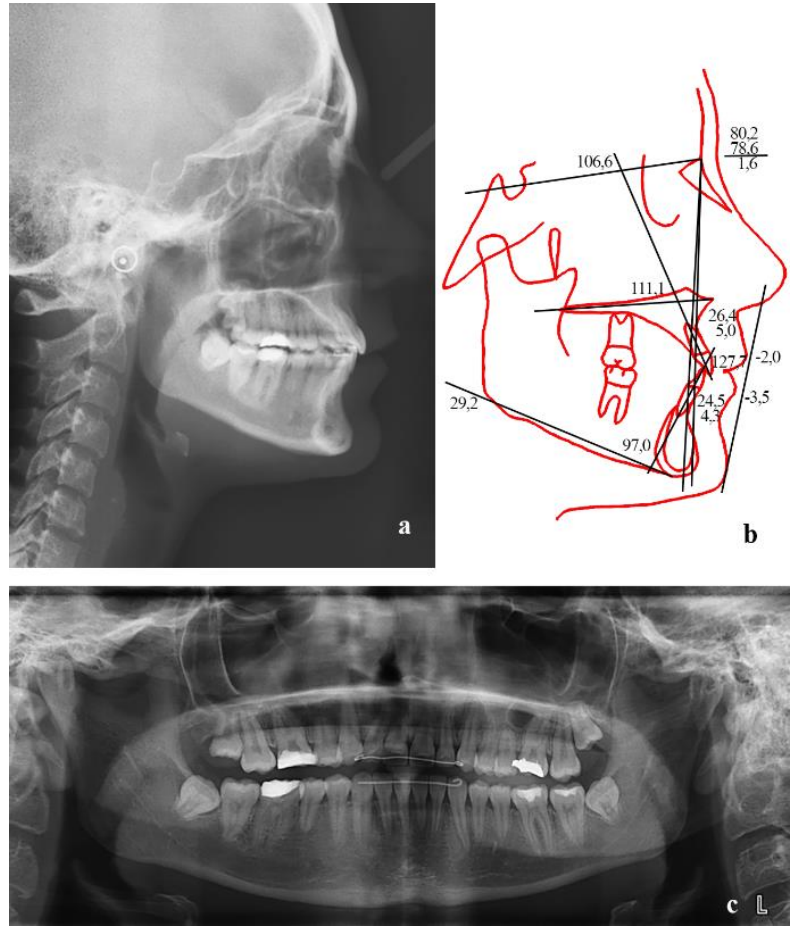

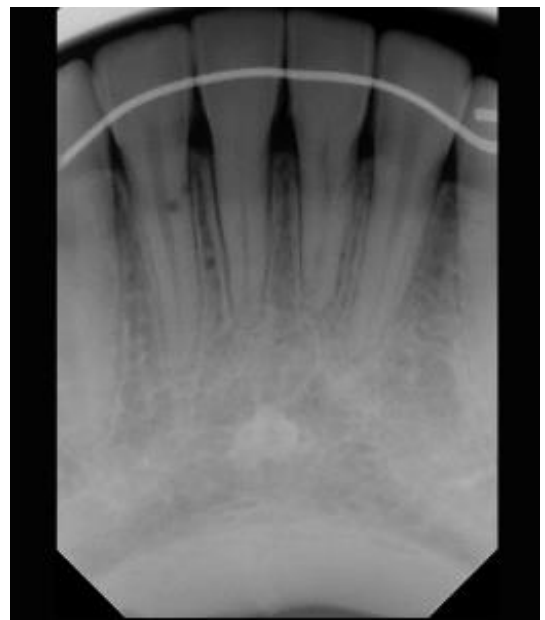

Resim 7.

12 ay sonra alınan periapikal radyograf

Resim 6.

Sabit ortodontik tedavi sonrası radyografiler ve analizler

a, b) Sabit ortodontik tedavi sonu lateral sefalometrik radyografi

ve analizi

c) Sabit ortodontik tedavi sonu panoramik radyografi 
Tablo 1.

Tedavi başı ve tedavi sonu dönemlerinde elde edilen lateral sefalometrik analiz verileri

\begin{tabular}{|c|c|c|}
\hline $\begin{array}{l}\text { Sefalometrik açı } \\
\text { ve milimetrik } \\
\text { ölçümler }\end{array}$ & $\begin{array}{l}\text { Sabit } \\
\text { ortodontik } \\
\text { tedavi } \\
\text { öncesi }\end{array}$ & $\begin{array}{c}\text { Sabit } \\
\text { ortodontik } \\
\text { tedavi sonu }\end{array}$ \\
\hline SNA $\left({ }^{\circ}\right)$ & 80,5 & 80,2 \\
\hline SNB $\left({ }^{\circ}\right)$ & 78,2 & 78,6 \\
\hline ANB $\left({ }^{\circ}\right)$ & 2,3 & 1,6 \\
\hline 1 - NA (mm) & 2,2 & 5 \\
\hline 1 - NA ( $\left(^{\circ}\right)$ & 17,2 & 26,4 \\
\hline 1 - NB (mm) & 3,2 & 4,3 \\
\hline $1-\mathrm{NB}\left({ }^{\circ}\right)$ & 21,8 & 24,5 \\
\hline $1-1\left(^{\circ}\right)$ & 138,5 & 127,7 \\
\hline GoGn - SN $\left({ }^{\circ}\right)$ & 29,5 & 29,2 \\
\hline Üst dudak - S(mm) & $-4,9$ & -2 \\
\hline Alt dudak - S(mm) & $-6,2$ & $-3,5$ \\
\hline IMPA( $\left.{ }^{\circ}\right)$ & 93,9 & 97 \\
\hline U1/PP( $\left.{ }^{\circ}\right)$ & 103,9 & 111,1 \\
\hline U1/SN( $\left.{ }^{\circ}\right)$ & 97,8 & 106,6 \\
\hline Witt's (mm) & 1,2 & 1,9 \\
\hline
\end{tabular}

\section{TARTIŞMA}

Günümüzde estetik kaygılar sebebiyle sabit ortodontik tedavi yaygınlaşmaktadır. Ancak dental travma prevalansının yüksek olması, bu istenmeyen durumun sabit ortodontik tedavi sırasında da meydana gelme intimalini arttırır. Literatürde dental travmaya sebep olan yaralanmaların en sık rastlanan sebepleri sırasıyla düşme ve yumruklaşma, spor kazaları ve trafik kazalarıdır. ${ }^{16}$ Bu vaka raporundaki olguda da geçirdiği senkop sebebiyle düşme sonucu sabit ortodontik tedavinin 5. ayında dental travma meydana gelmiştir.

Dental travma geçiren bireylerde her zaman ilk öncelik diş ve çevre dokuların tedavisi olmayabilir. Aciliyet durumuna göre vakaların diş tedavisi hemen gerçekleştirilemeyebilir. ${ }^{17} \mathrm{Bu}$ raporda sunulan vaka da, senkop sonucu düşme sebebiyle geçirdiği dental travmanın tedavisi için kliniğimize ancak iki gün sonra gelebilmiş ve hastanın dudaklarında büyük ölçüde iyileşen ancak dikkat çeken laserasyon tespit edilmiştir (Resim 3).
Literatürde travmatik dental yaralanmanın postnormal oklüzyon, 4 mm'yi geçen artmış overjet, kısa üst dudak, yetersiz dudaklar ve ağız solunumu ile ilişkili olduğu ve daha ağır yaralanma (dentin kırı̆̆ı, pulpa lezyonu, kök kırığı, total avülsiyon [eksartikulasyon]) gösteren olgularda ortalama overjetin $5 \mathrm{~mm}$ ' nin üstünde olduğu raporlanmıştır. ${ }^{16}$ Maksiller keser dişin (\% 87.9) dental travmadan en çok etkilenen diş olduğu bildirilmektedir. ${ }^{18}$ Ancak bu vaka raporunda sunulan vakada dental travma alt keser bölgede meydana gelmiştir. Sunulan bu vaka raporu doğrultusunda overjetin travma açısından önemli bir predizpozan faktör olduğu, ${ }^{16}$ ancak dental travma oluşmasında da tek etken olmadığı söylenebilir.

Bu raporda sunulan vakada dental travma sonucu mandibuler sağ ve sol santral dişlerde ve çevre dokularında yaralanma ve bu dişlerde lingual yönde lateral lüksasyona eşlik eden ekstrüzyon meydana gelmiştir. Bauss ve ark. ${ }^{6}$ sabit ortodontik tedavi sırasında keser dişlerde lateral lüksasyon veya ekstrüzyon görülme sıklığını \% 17 olarak bildirmiştir.

Travma sonrası yapılan radyolojik değerlendirmede herhangi bir kök veya kron kııı̆ının olmadığı belirlendikten sonra dişler üzerindeki aktif ortodontik kuvveti kaldırmak amacıyla travma kuvvetinin etkisiyle alt çenede eğilmiş olan $0.016 \times 0.022$ inç paslanmaz çelik ark teli çıkartılmıştır. Sunulan vakada dental travma sonrası yapılan vitalometri testinde sonuç negatif çıkmıştır. Travmaya uğramış dişlerin çoğu, başlangıç incelemelerinde elektrik uyaranına cevap vermeyebilir. ${ }^{19}$ Ancak zaman içinde sublüksasyonlu ve daha az olmak üzere lüksasyonlu dişlerde vitalite testinde negatiften pozitife doğru yanıt değişiminin görüldüğü bildirilmiştir. ${ }^{8} \mathrm{Bu}$ nedenle negatif yanıt tek başına nekroz bulgusu olarak değerlendirilmemiş, kanal tedavisi hemen yapılmamış, bekleme süresi içerisinde krondaki renk değişimi, negatif hassasiyet testi ve periapikal radyolusensi gibi en az bir başka klinik, radyografik pulpa nekrozu belirtisi oluşana dek endodontik tedavi ertelenmiştir.

Travmaya uğramış dişler aktif ortodontik kuvvetin dışında bırakılarak repoze edilemeden esnek retainer teli ile lingualden splintlenmiştir. Bauss ve ark. ${ }^{6}$ travma sonucu lateral lüksasyon meydana gelen vakalarda travma görmüş dişlerin ve soket duvarlarında meydana gelen kırıkların dikkatlice repoze edildiğini ve 0.016 x 0.022 inç kalınlığındaki paslanmaz çelik ark teli ile dişlerde fiksasyon yapıldığını belirtmişlerdir. Üç haftalık fiksasyon süresince travma görmüş dişler yanındaki dişlere splintlenmektedir. ${ }^{6}$ Owtad ve ark. ${ }^{5}$ ise travma görmüş dişin kronunun palatinale kökünün ise labiale displaze olduğu lateral lüksasyon durumunda dişin, lokal anestezi altında repoze edildikten sonra hafif esnek bir splint ile 4 hafta boyunca stabilize edilmesini, endodontik kanal tedavi yapılmasını ve ortodontik tedaviye 6 ay sonra devam edilmesini önermişlerdir. Bu vaka raporunda sunulan vakada mandibuler santral dişlerin kronu linguale yer değiştirdiği sırada bu dişlere komşu sağ ve sol lateral dişler de birbirine yanaştığından ve lateral lüksasyon sonucu yer değiştiren dişlerin yerini kapatması sebebiyle (Resim 3) alt santral keser dişler olması gereken yerlerine doğru repoze edilememiş ve oldukları yerde esnek retainer teli ile splintlenmişlerdir. Esnek splint, lateral lüksasyona eşlik eden 
ekstrüzyon durumunda güncel olarak kullanılmaktadır. ${ }^{20}$ Ortodontik tedavi görmeyen dişlerde travma sonrası splintleme gerektiren kök kırığı, alveoler kırık için splintin dişlerde kalma süresinin 4 hafta - 4 ay, sublüksasyon, ekstrüziv lüksasyon için 2 hafta, lateral lüksasyon için 4 hafta, intrüziv lüksasyon için ise 4-8 hafta olması gerektiği bildirilmiş ve esnek splint kullanımı önerilmiştir. ${ }^{20}$ Ancak bu raporda bahsedilen vaka, sabit ortodontik tedavi gören bir vakadır. Bu vaka raporunda ilk 4 hafta hiçbir dişe aktif kuvvet uygulanmamış, travma görmüş dişler esnek tel ile splintlenmiş, yanında bulunan dişler ise kalın kesitli NiTi ark teli ile yerinde tutulmuştur. Bu esnada alt santral kesici dişlerin yeri pasif açık coilspring ile tutulmuştur. Dört hafta sonra ise travma görmüş dişlerdeki esnek tele dokunulmadan yandaki dişlere aktif kuvvet uygulanmaya başlanmıştır. Yandaki dişlere aktif kuvvet uygulanması ve travma görmüş dişlerin aktif dil kuvvetlerinin altında olması sebebiyle esnek splint travma görmüş dişlerden bekleme süresi boyunca çıkartılamamıştır.

Lateral lüksasyon görülen hastalarda travmanın ciddiyetine göre travma görmüş dişlerde ortodontik tedaviye 3 ila 12 ay 'dan önce başlanmaması gerektiği aksi halde ankilozla karşılaşılabileceği belirtilmiştir. ${ }^{7} \mathrm{Bu}$ nedenle hastamızda travma görmüş olan dişlerine ortodontik kuvvet uygulanması yedi ay süre ile durdurulmuş ve dişler ve pulpal durumları bu süreçte izlenmiştir.

Dental travmadan yedi ay sonra mandibuler santral kesici dişlerin lingualine yapılan esnek splint dikkatli bir şekilde sökülmüştür. Yapılan vitalite testi pozitif yanıt vermiş, kanal tedavisi yapılmasından vazgeçilmiştir. Bu durum travma sonucu lateral lüksasyona eşlik eden ekstrüzyon vakalarında endodontik tedavinin zamanlaması ile ilgili acele edilmemesi gerekliliğini göstermektedir. Alt santral kesici dişlere açık coilspring ile yeteri miktarda yer açıldıktan sonra bu dişler en ince ark teli ile seviyelenmeye başlanmıştır.

Mandibuler santral keserlerin olması gereken konuma hareket ettirilmesi sırasında hafif kuvvetler tercih edilir. ${ }^{5}$ Ark teli seçiminde ilk tercih sıklıkla 0.012 inç NiTi ark teli olmaktadır. ${ }^{6}$ Dişlerin 7 aylık bekleme süresi sonrasında ankiloz olması intimaline ve aktif ortodontik kuvvet uygulaması ile hareket etmemesi ihtimaline karşı alternatif yaklaşımlar cerrahi lüksasyon, cerrahi repozisyon ya da alveoler distraksiyon olabilir. ${ }^{21}$ Ancak bu vaka raporunda sunulan vakanın alt santral kesici dişleri 7 aylık süreç sonrası 0.012 inç NiTi ark teli uygulanması ile hareket etmiştir. Ardından ark teli 5 haftada bir kalınlaştırılmıştır. Genellikle travma görmüş dişlere uygulanacak aktif ortodontik kuvvetin süresinin kısa, şiddetinin ise az olması tercih edilmektedir. ${ }^{5,6}$ Bunun sebebi ortodontik kuvvet uygulaması öncesi dental travma gören dişlerde ortodontik tedavi sonunda kök rezorbsiyonu, pulpa obliterasyonu ve nekrozu riskinin olmasıdır. ${ }^{7,22}$

$\mathrm{Bu}$ vaka raporunda sunulan vakada mandibuler santral kesici dişlere travma sonrası hafif kuvvetler uygulanarak yapılan sabit ortodontik tedavi, ideal okluzyonun elde edilmesi ile başarılı bir şekilde bitirilmiştir. Hastanın 12 ay sonraki kontrolünde de herhangi bir devitalizasyon veya kök rezorbsiyonu tespit edilmemiş ancak alınan periapikal radyografide kök kanallarında kısmi pulpa obliterasyonu gözlenmiştir (Resim 7). Vakanın alt keser dişlerinde ilerleyen zamanlarda oluşabilecek pulpal nekroz ve kök rezorpsiyonu intimali sebebiyle 6 aylık rutin kontrollerinin yapılmasına karar verilmiştir.

Aslında bu vakada travma meydana geldiğinde dişlerde braket ve ark telinin olması ve tedavisinin sıralama seviyelenmenin tamamlandığı ve kalın ark teline geçildiği bir zamanda olması avantajdır. Braketlere ligatürlü kalın ark teli belki de çarpmanın etkisi ile dişlerin kırılması ve/veya avülse olma intimalini azaltmış olabilir. Ortodontik tedavi sırasında dişlerin etrafındaki kemikte meydana gelen apozisyon ve rezorpsiyonlar dişlerin kökleri ile onu çevreleyen alveol kemiği arasında bir aralanma meydana getirmektedir. Bu da travmanın sebep olduğu ani ve şiddetli kuvvetin mevcut periodontal aralık genişliği sebebiyle dokuların esnemesine, diş ve çevre dokularda sebep olabileceği diş ve/veya kemik kırığı intimalinin azalmasına sebep olmuş olabilir; diş, alveol kemiği içerisinde az da olsa esnemiş olabilir. Ek olarak ortodontik tedavi sırasında kemik içindeki apozisyon ve rezorpsiyon olayları sırasında kemik ve dentin de aktif devam eden yapım-yıkım döngüsü, travma sonrası iyileşmenin de hızı olmasını sağlamış olabilir. ${ }^{23}$ Bekleme süresi sonrası uygulanan aktif ortodontik kuvvetin hem hafif hem de kısa süreli olması travma görmüş dişlerin sağlıklı olarak ağızda kalma süresini arttırabilir. Ancak yine de elde edilecek başarı dental travmanın şiddetine ve vakanın bireysel iyileşme cevabına bağlıdır. Travma tedavisi yapıldıktan sonra travma gören dişlerde sabit ortodontik tedavi ile elde edilecek tedavi sonucunun başarısı ve kalıcılığı, hem hasta hem de hekimin başarısı açısından önem taşımaktadır. 


\section{KAYNAKLAR}

1. Glendor U. Epidemiology of traumatic dental injuries a 12 year review of the literature. Dent Traumatol 2008; 24: 603-11.

2. Lam R. Epidemiology and outcomes of traumatic dental injuries: a review of the literature. Aust Dent $\mathrm{J}$ 2016; 61: 4-20.

3. Schwartz-Arad D, Levin L, Ashkenazi M. Treatment options of untreatable traumatized anterior maxillary teeth for future use of dental implantation. Implant Dent 2004; 13: 11-9.

4. Poi WR, CardosoLde C, de Castro JC, Cintra LT, Gulinelli JL, de Lazari JA. Multidisciplinary treatment approach for crown fracture and crown root fracture a case report. Dent Traumatol 2007; 23: 51-5.

5. Owtad P, Shastry S, Papademetriou M, Park JH. Management Guidelines for Traumatically Injured Teeth during Orthodontic Treatment. J Clin Pediatr Dent 2015; 39: 292-6.

6. Bauss O, Röhling J, Meyer K, Kiliaridis S. Pulp vitality in teeth suffering trauma during orthodontic therapy. Angle Orthod 2009; 79: 166-71.

7. Kindelan SA, Day PF, Kindelan JD, Spencer JR, Duggal MS. Dental trauma: an overview of its influence on the management of orthodontic treatment. Part 1. J Orthod 2008; 35: 68-78.

8. Andreasen JO, Andreasen FM, Andersson L, eds. Text book and Color Atlas of Traumatic Injuries to the Teeth. Oxford, UK: Blackwell Publishing; 2007: 669715.

9. Malmgren O, Malmgren B. Orthodontic management of the traumatized dentition. In: Andreasen JO, Andreasen FM, Andersson L, eds. Textbook and Color Atlas of Traumatic Injuries to the Teeth. Oxford, UK: Blackwell Publishing;2007: 669-715.

10.Atack NE. The orthodontic implications of traumatized upper incisor teeth.Dent Update 1999; 26: 432-7.

11.Bauss O, Röhling J, Sadat-Khonsari R, Kiliaridis S. Influence of orthodontics intrusion on pulpal vitality of previously traumatized maxillary permanent incisors. Am J Orthod Dentofacial Orthop 2008; 134: 12-7.

12. Mendoza A, Solano E, Segura-Egea JJ. Treatment and orthodontic movement of a root-fractured maxillary central incisor with an immature apex: 10year follow-up. Int Endod J 2010; 43: 1162-70.

13.Lee R, Barrett EJ, Kenny DJ. Clinical outcomes for permanent incisor luxations in a pediatric population. II. Extrusions. Dent Traumatol 2003; 19: 274-9.

14. Erdemir A, Ungor M, Erdemir EO. Orthodontic movement of a horizontally fractured tooth: a case report. Dent Traumatol 2005; 21: 160-4.

15.Linge L, Linge BO. Patient characteristics and treatment variables associated with apical root resorption during orthodontic treatment. Am J Orthod Dentofacial Orthop 1991; 99: 35-43.
16. Forsberg CM, Tedestam G. Etiological and predisposing factors related to traumatic injuries to permanent teeth. Swed Dent J 1993; 17: 183-90.

17. Crain EF,Gershel JC, editors. Clinical Manual of Emergency Pediatrics. 5th ed. Cambridge University Press, December 2010.

18.Zaragoza AA, Catalá M, Colmena ML, Valdemoro C. Dental trauma in school children six to twelve years of age. ASDC J Dent Child 1998; 65: 492-4.

19.Gopikrishna V, Pradeep G, Venkateshbabu N. Assessment of pulp vitality: are view. Int $\mathrm{J}$ Paediatr Dent 2009; 19: 3-15.

20.Diangelis AJ, Andreasen JO, Ebeleseder KA, Kenny DJ, Trope M, Sigurdsson A, et al. International Association of Dental Traumatology. International Association of Dental Traumatology guidelines for the management of traumatic dental injuries: 1. Fractures and luxations of permanent teeth. Dent Traumatol 2012; 28: 2-12.

21.Şenışık NE, AkalınY. Dental Ankylosis: Treatment Options. EÜ Diş Hek Fak Derg 2016; 37: 75-87

22. Kugel B, Zeh D, Mussig E, Incisor trauma and the planning of orthodontic treatment. J Orofac Orthop 2006; 67: 48-57.

23. lino S, Sakoda S, Ito G, Nishimori T, Ikeda T, Miyawaki S. Acceleration of orthodontic tooth movement by alveolar corticotomy in the dog. Am J Orthod Dentofacial Orthop 2007; 131: 448-8.

Yazışma Adresi:

Dt. Filiz Aydoğan

Süleyman Demirel Üniversitesi

Diş Hekimliği Fakültesi, Ortodonti AD

Isparta, Türkiye

Tel : +902462113353

Faks : +902462370607 